\title{
Geovisual Analytics in School: Challenges for the Didactic Design of the Classroom
}

\author{
Linnéa Stenliden
}

\begin{abstract}
This paper aims to determine the distribution of problem spaces in learning activities, when geovisual analytics is introduced into social science education. We know that various dimensions of complexity emerge in learning activities including this kind of technology. This paper clarifies the features of the problem spaces in such activities. The study was conducted in three middle schools in Sweden, in four social science classes with students aged 10 to 13 years. The specific geovisual analytics platform used was Statistics eXplorer. The learning activities were followed for two to four weeks at each school using video observations. Drawing on actor-network theory, we conducted material discursive analyses of the learning activities. The geovisual analytics generally support student understandings, but the didactic design of the classroom was not completely supportive. Six central aspects were found in the distribution of problem spaces within the learning activities. Novel approaches to pedagogy and teaching employing geovisual analytics could benefit students' knowledge building as they work with visualized data.
\end{abstract}

Index Terms - Geovisual analytics, visual data, statistics, visual storytelling, problem spaces, pedagogy, instruction, analytical reasoning.

\section{INTRODUCTION}

Nowadays, the abilities to store, aggregate, and combine digital data, and then to use these data to perform analyses, have become essential. These skills are needed as they may enable citizens to make sense of and participate in our data-driven and complex society [1]. As digital data are everywhere and can create puzzling conditions for us, how are we to grasp them and draw conclusions from them? This increasingly complicated situation is posing growing challenges as the volumes of data are not only huge but are growing rapidly [2]. Furthermore, the scale and scope of this rapid proliferation of data are set to expand greatly, as various technology trends are also accelerating and converging [2]. All of this places great demands on education [3]. Especially in social science education, but also in other subjects, teachers and students struggle to analyze available data in order to teach and learn about conditions in society. One challenge is to support both teachers' and students' activities in sorting, valuing, and analyzing information when organizing teaching and learning about the complex world of today.

New methods and technologies, such as geovisual analytics

Manuscript received January 10, 2017; revised April 29, 2017. The research was in part supported by funding from the Research School of Childhood, Learning and Didactics (RSCLD), Educational Sciences (grant no. 721-2007-3671), and the Swedish Agency for Innovation Systems (VINNOVA).

L. Stenliden is with the Department of Social and Welfare Studies at Linköping University, Sweden (e-mail: linnea.stenliden@liu.se).
(GVA), are being developed to help us cope with this information overload, and these may support certain teaching related objectives in school. GVA is not only an umbrella term for technology that attempts to visualize information while reinforcing analytical reasoning, argumentation, and knowledge building [4]; it is also the name of an emerging interdisciplinary research field that integrates perspectives from geographic information science and visual analytics [4]. In the present study, a GVA visual storytelling method (Figure 1) is introduced to social science teachers. This technology can be seen as offering means to support both teachers' "transposition" of "raw material/information" [5] and students' "visual analytical reasoning." Introducing a technology into an educational setting, like the examined one, will always affect other parts of the educational system in some way, but the direction in which this happens is difficult to foresee [6]. Therefore, it becomes important to find out how learning activities and education actually change when a GVA platform is introduced. This may help teachers meet demands to develop students' ability to handle and analyze large amounts of data [1], and can make valuable contributions to both classroom instruction and learning processes [7]. To this end, the present study examines learning activities involving a GVA platform in social science classrooms. The aim is to determine the distribution of problem spaces in the learning activities when GVA is introduced into social science education. The following research questions are addressed:

1) What learning activities emerge when methods for visual storytelling technology are employed in social science education?

2) What features do problem spaces in the learning activities have when methods for visual storytelling technology are employed?

In turn the answers may help identify certain consequences of GVA for the didactic (the teaching) design.

\section{Digital Resources AND GeOvisual ANALYTICS IN SCHOOLS}

In the "digital age," images and the visual have increased in importance and information mediated through texts has lost some of its privileged status. This development has also influenced the conditions for children's learning in schools [cf. 8]-[10]. The interaction with semiotics as a visual language, easily facilitated by digital resources such as computers, renegotiates how learning and knowledge are seen in classrooms. This is in line with the extensive research into learning and educational technology that illustrates how teaching/learning models in school need to be adjusted when 
digital technology is introduced [11], [12].

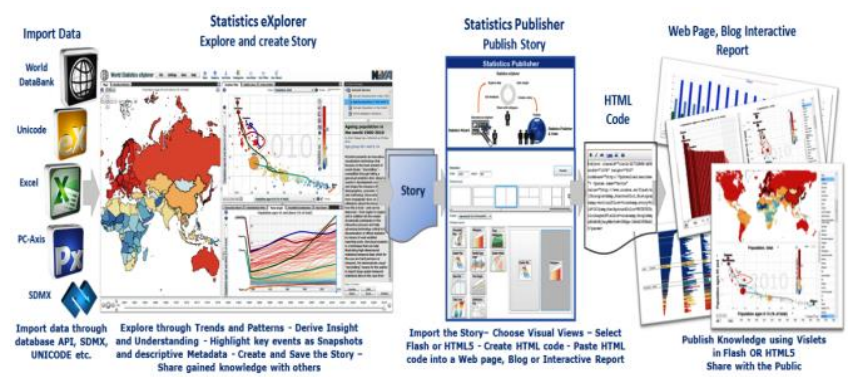

Fig. 1. The introduced GVA platform is Statistics eXplorer, which makes it possible to import statistical data from official databases, explore and gain insight into the data, create a visualized story, and publish the visual story on a blog or website (Image: Mikael Jern, Liu).

Research also identifies another issue: students are not always being provided with a consistent and measured view of the world supported by sufficient tools [13]. Teaching is not being done correctly, visually or perceptually, supported by appropriate information resources. Reynolds and Vinterek [13] argue that students must develop their visual abilities and literacy to be able to interpret, analyze, and use visuals in more developed ways. A shift towards the visual, challenging traditional schooling and education, has been identified by Johansson et al. [14]. They found that digital (visual) resources create various interactions in the classrooms when implemented, and that practices must adjust to the new requirements associated with such technology and awareness. At the same time, traditional writing is still the dominant mode in school, at least in primary and secondary education, when it comes to interacting with information and expressing insights, as there is no common basis for working with other modes of knowledge expression. A larger study [14] found that traditional writing pedagogy can disrupt the development of ability in digital and multimodal texts. Another study [12] demonstrated that even though students used various multimodal representations, such as sound and moving pictures, in their work, these were not featured or included when the work was handed in to teachers, when it was the written texts that dominated.

The GVA research field is described as an attempt to combine automatic and visual analytical methods with interaction between humans and data [4], [15]. The idea is to take advantage of the understanding that "computers are incredibly fast, accurate, and stupid. Human beings are incredibly slow, inaccurate, and brilliant. The marriage of the two is a force beyond calculation" [16]. In a visual exploration process, the analyst (i.e., a student) and the visualization tool interact to achieve insight by translating information into understanding. Examples of such tools include Gapminder [17] and the Statistics eXplorer platform [18]. Students' visual ability could be employed more frequently and systematically in schools by using such GVA tools. So far, however, little attention has been paid to issues concerning the use of GVA tools in school environments [18].

We argue that various recently developed ways of collecting, organizing, and manipulating digital data have opened our eyes to new abstract facts, complexities, and realities. Meanwhile, teachers' and students' understanding is usually still struggling in the primary world of physical objects, face-to-face communication, and people interacting directly in traditional schooling/education. One way to address this deficiency would be to introduce GVA tools in school to support learning activities. So far, we only know that different dimensions of complexity are found in learning activities incorporating GVA and that there is a need for deeper insight [19]. We lack studies that examine in depth what happens when teachers, students, and GVA interact to process information for the purpose of fostering understanding among students. Such research would require specialized theories to guide the work.

\section{Theoretical Stance: Actor-Network TheOry}

By drawing on actor-network theory (ANT), learning activities can be investigated and analyzed in relation to how both social actors (i.e., teachers and students) and material actors (i.e., technology as well as other objects and matters) jointly form activities [20]. This means that the interactions between these various actors (e.g., students, technology, teachers, educational content, and assignments), or rather actants (a concept that broadens the outlook to encompass all entities), are rendered significant [6].

\section{A. Learning Activities: Interactions That Constitute a Network}

What is studied is how actants engage in collaborative tasks, with the term learning activity referring to all interactions between the actants. Emerging interactions between actants constitute a network, which appears due to the actants' ability to collaborate in pursuit of their interests. This means that classroom activities are not regarded as performed under set conditions in a given social context; instead, the possible actions of all actants are regarded as constructing the learning activities in the network [21].

\section{B. Translations and Problem Spaces}

In ANT, manifestations of actants' interactions are called translations. These can be varied in nature, but have in common that they are used to tie the actants together [21]. Translations can be seen as comprising several phases or "moments":

1) Problematization happens when an actant attempts to define the nature of the problem and the roles of other actants to fit the solution proposed.

2) Interessement can take place in a series of processes that attempt to impose the identities and roles defined in the problematization process onto other actants.

3) Enrolment may ensue, leading to the establishment of alliances among the actants. For enrolment to be successful, however, more than just one set of actants imposing their will on others is required; it also requires that these others yield.

4) Mobilization can occur as the proposed solution gains wider acceptance and an even larger network of absent entities is created through some actants acting as spokespersons for the others.

Every connection through interaction between actants is part of a translation, causing a transformation of what has been articulated. This is not necessarily a sequential process, 
and a process of translation does not necessarily result in a complete translation. In this study, the term problem space is used to refer to the situation that can occur in a translation before it is complete - if it ever achieves completion (cf. Gill and Hicks [22] who define the term slightly differently due to a different theoretical approach). Here, problem space refers to the moments when students and other actants attempt to define both the nature of the problem and the roles of other actants to fit the task of the assignment. The concepts of translation and its "moments" and the term problem space are analytical tools used here to describe the associations between technology, students, teachers, and classrooms.

\section{METHOD}

When studying situations as complex as educational practice, it is important to acknowledge that it is impossible to find a single way to understand the manifold constituent processes. The school serves as a locus of multiple and intersecting demands that exceed the tasks of both the teachers and students.

The schools examined here were not selected according to any special criteria, as all schools and classrooms differ from all others. The study was accordingly carried out in three randomly chosen middle schools in Sweden. Altogether, four teachers and their four classes, comprising 98 students aged 10 to 13 years, participated. The GVA tool used was the Statistics eXplorer platform. The learning activities were followed in all social science classes for a period of two to four weeks at each school.

\section{A. Data Communication Technology}

The Statistics eXplorer platform has a conceptual approach based on three complementary activities: a) data downloading, b) storytelling, and c) publishing. Data, in the form of official statistics, are normally preloaded from official databases (with a set of basic indicators) [18]. The visualizations facilitate information and geographical visualization methods. The platform's storytelling functions allow teachers to gain insights and customize the data downloading, accomplishing various things: 1) Teachers can access statistical data from, for example, the World DataBank (a database of official statistics) through a direct API interface. 2) They can explore and make discoveries through examining trends and patterns to derive insight. The discoveries that the teachers make can be documented with snapshots and associated descriptive metatext and accessed via hyperlinks; in addition, external web links to relevant information can be attached. 3) Teachers can create stories in which visual discoveries are captured by snapshots together with descriptive metadata and hyperlinks in relation to the analytical reasoning. 4) Finally, teachers can share the story with colleagues or students by publishing the story embedded in educational blogs or HTML pages. This process is described as the visual storytelling process. The published material is called a "Vislet": a small visualized digital book with an interactive and DynaLinked interface.

\section{B. Data Use, Data, and Task Characteristics}

The study was conducted in two phases. In phase one, the teachers were introduced to the Statistics eXplorer platform.
Six training occasions were organized for the teachers in which they learned how to maneuver the visual storytelling features of the platform. The teachers made lesson plans according to the Swedish social science curriculum; they downloaded official statistics related to the educational goals and organized the content and tasks using visual storytelling methods. The official statistics that the teachers chose to interact with came from databases related to Statistics Sweden (SCB), the Organization for Economic Co-operation and Development (OECD), the World Health Organization (WHO), and the World DataBank. The Vislets that the teachers produced were published on a blog shared by the participating schools. The Vislets concerned 1) living conditions in Sweden-differences and similarities, 2) living conditions in Europe, focusing on aspects of population, education, work, and economics, and 3) global issues such as energy use, water access, and the environment. In addition various assignments were given that concerned socio-scientific issues such as comparing one's own living conditions with those of people in the rest of Sweden, Europe, or the world. In phase two, the teachers used the Vislets in their social science classes. The learning sequences usually began with the teacher introducing the content or instructing the students on how to proceed. Then the students worked in pairs. They tried to complete the assignments posted by the teacher in the Vislets. The classrooms were equipped in three different ways: one classroom had five stationary computers; one had a laptop connected to a smart-board and students had access to a form room equipped with desktop computers; and a third classroom (used by two classes separately) had 15 laptops and a digital projector. As this study views classroom activities not as being determined by specific set conditions in a given social context, it is not the differences in student behavior due to the different settings that are of interest. Instead, the focus is on the possible actions of all actants who construct the learning activities in the environment. The various configurations of computer equipment can be regarded as representing various classrooms.

\section{Empirical Data}

Documentation and analysis methods that advance knowledge of the actants' interactions and their relationships during the activities are of particular interest when studying the use of media technology [23]. In response, video observations were made that facilitated thorough documentation of actants. All the lessons in social science at the participating schools were followed using an ordinary video camera. Camtasia Studio [24] was used to record the students' computer screens to capture the activities in detail. In all, the empirical material comprises 42 session recordings made at close range, showing students together with computer screen captures $(22.2 \mathrm{~h})$ and 35 overview recordings of the classroom $(16 \mathrm{~h})$.

\section{Analysis}

It is not enough to observe the working practices of domination when studying school practices; instead, one must grasp the complexities and the unexpected to begin to understand what is and/or is not in the process of becoming. Hence, the sessions selected for analysis were selected not in 
relation to representation but in relation to what is called intensification [25], in an attempt to avoid the dichotomies and singular conceptions of agency that often structure analyses. Instead, the purpose was to find ways of engaging that were more attuned to the unexpected, shifting connectivity of time, place, persons, and objects.

To guide the analytical work further, three ANT principles were used [21]. First, a matter of style means not selectively censor the actants (e.g., teachers, students, the application, and official statistics) when they are expressing themselves. Consequently, no predefined analytical categories were used in managing the data. Second, generalized symmetry means that the same vocabulary should be used to describe social and material objects. The terminology has accordingly been carefully considered when writing up the analyses. Third, free association entails abandoning all a priori distinctions between natural and social events, so the goal is not to make distinctions between different actants and their actions. The empirical data have been analyzed using the concepts mentioned earlier, i.e., translation, problematization, interessement, enrolment, and mobilization as well as problem space. The focus was on all learning activities emerging in the networks. The three excerpts presented in the following section were selected due to their clear illustration of what the paper is examining.

\section{RESULTS}

The analyses show that the emerging learning activities in the classrooms are constructed by deeply intertwined interactions between the various actants in the classroom. These multiparty interactions constitute a network as the actants attempt to translate. As this happens, various problem spaces also emerge. Six aspects are found to be central to the distribution of these problem spaces:

- the task characteristics related to instruction/ discretion;

- the data type related to the focus area; and

- the performer dependence linked to data use.

It is important to note that the highlighted aspects do not appear as separate pairs; although they are presented as such here and in the excerpts, this is only for the sake of clarity. In the transcriptions that follow, comments about what is happening are shown in brackets, for example, "[He reads the screen...], and the articulations of the non-human actors are underlined to indicate that they are not human speech, for example, "Screen: Poor and rich countries."

\section{A. The Task Characteristics Related to Instruction/ Discretion}

First, a common problem space in the learning activities has been found to emerge in relation to instructions or the level of discretion together with the characteristics of the task. This is illustrated by the following example, in which two students work together with a Vislet concerning infant mortality and population growth; it illustrates the importance of understanding the task and the task's concepts.

Excerpt - network 1: What are we supposed to do?

Turn Actant Action

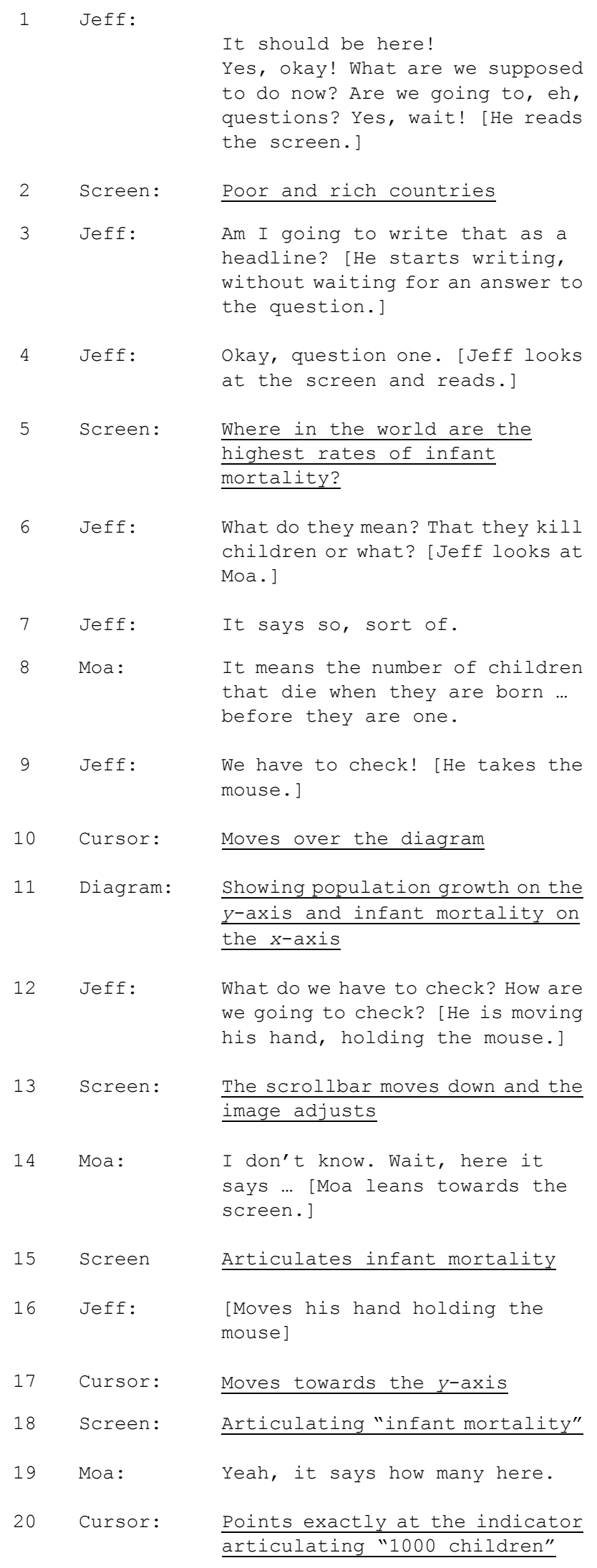

Initially, the students attempt to organize the activity (see turns 1 to 4 ). They are trying to find out what to do and how to deal with the task and learning content they will eventually encounter - this is problematization (in which the actants attempt to define the nature of the problem and the roles of other actants to fit the proposed solution). The students then try to interpret the task more thoroughly (see turns 5 to 8 ). Here they scrutinize the concept of infant mortality further 
using questions, wonderings, and the visualizations, which together can be seen as interessement (in which the various actants try to impose the identities and roles defined in the problematization onto other actants). The interessement seems to create further curiosity and serves as a driving force, as when Jeff in turn 9 says, "We have to check!" Here the enrolment phase begins, as the concept is investigated by the establishment of allies between the actants (i.e., the mouse, cursor, screen, and students, see turns 10 to 14).

This indicates that these tools and the visualized data enhance the students' ability to succeed in the problem space. By means of the actants' interactions, the students are able to understand the concept of infant mortality, for example, when the screen/visualization and Moa in turns 13, 14, and 15 interact and align. The non-human actants seem to direct the students' gazes to the visualized data. By means of the interactions and alignments between the actants, the information is translated (see also turns 16 to 20). The students seem to have established an understanding of the task and the task's concepts with the support of the tool. As long as the students are unsure of what to do or how to interpret the concept of "infant mortality," it is difficult for them to proceed in the problem space. This illustrates the importance of students understanding the task and its concepts, as the relationship between the instructions or level of discretion and the task characteristics seems to significantly support the translation between the actants.

\section{B. The Data Type Related to the Focus Area}

Second, another kind of problem space that often emerges in learning activities concerns the focus area in relation to the data type (i.e., how the information was visualized). The issue is how to understand the relationships between the learning content, concepts, graphics, and semiotics. This is illustrated by a continuation of the first excerpt.

Excerpt - network 2: How are we supposed to look?

\begin{tabular}{|c|c|c|}
\hline Turn & Actant & Action \\
\hline 1 & Jeff: & $\begin{array}{l}\text { Okay, but how should we look, } \\
\text { then? }\end{array}$ \\
\hline 2 & Moa: & $\begin{array}{l}\text { I don't know. [Jeff looks at the } \\
\text { screen and reads.] }\end{array}$ \\
\hline 3 & Screen: & $\frac{\text { Infant mortality per } 1000}{\underline{\text { children }}}$ \\
\hline 4 & Jeff: & Oooh ... that's a lot \\
\hline 5 & Cursor & $\begin{array}{l}\text { Moves down and tooltips one of the } \\
\text { bubbles }\end{array}$ \\
\hline 6 & Screen: & Articulates Switzerland \\
\hline 7 & Jeff & $\begin{array}{l}\text { Only four per thousand. [Jeff } \\
\text { articulates firmly and with } \\
\text { concentration.] }\end{array}$ \\
\hline 8 & Cursor: & $\begin{array}{l}\text { Moves upwards and tooltips a } \\
\text { bubble }\end{array}$ \\
\hline 9 & Screen: & Articulates Great Britain \\
\hline
\end{tabular}

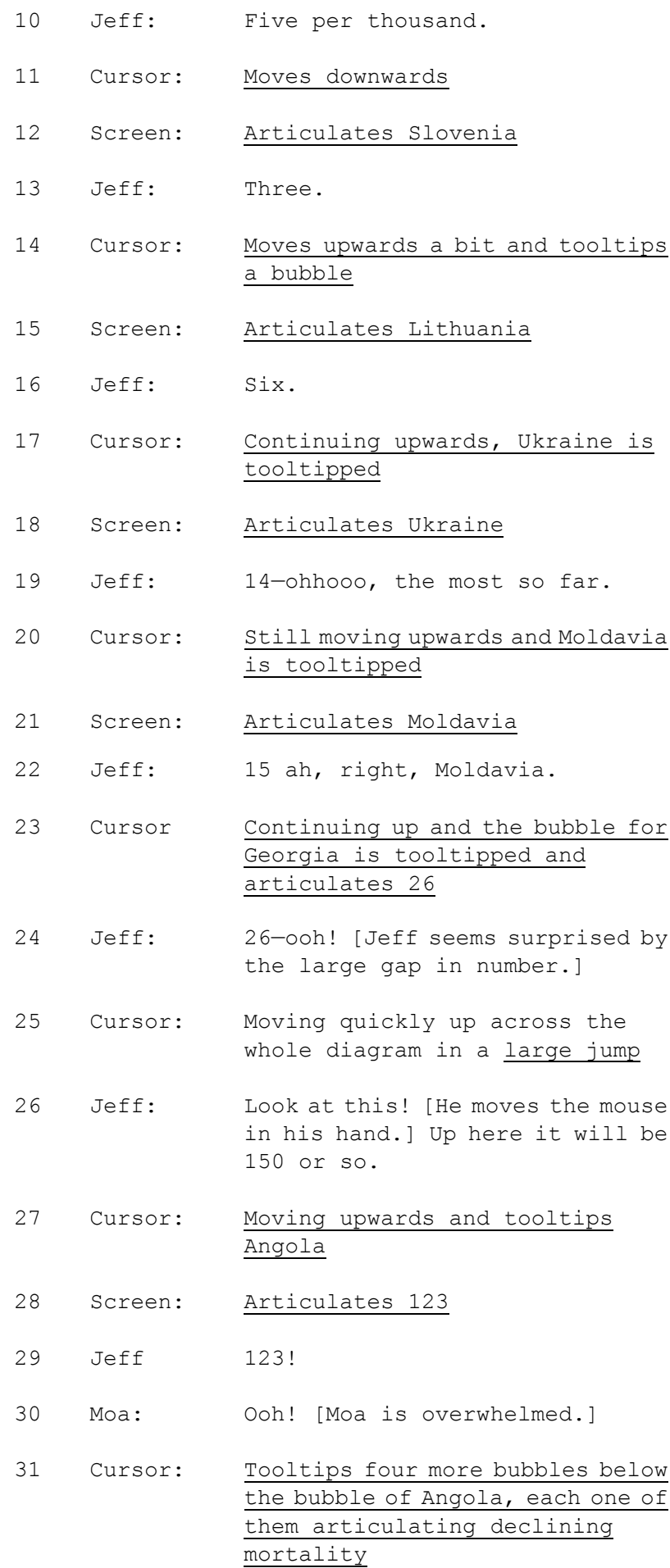

Here, in this network of interactions, Jeff is asking in turn 1 "how" they are supposed to look for the information; this indicates that the relationships between the data type/visualized information and the focus area are essential. Here Jeff is problematizing how they are going to proceed, and the question he raises indicates that it is not clear to him what kind of data is linked to infant mortality, which is the focus area. Moa's uncertainty in this problematizing (see turn 2) underlines this, and indicates that they first must understand how the information is visualized, then be able to interpret something about the focus area. By investigating the bubbles articulated in the graph, which presents countries and their infant mortality rates, the students move to the interessement phase. They successively seem to understand 
how the relationships between the learning content, concepts, and graphics work (see turns 3 to 22). These turns between the actants show this progression step by step. They enrol together and establish an alliance that creates a translation or an understanding of "how to look" at the diagram. For enrolment to be successful, however, more than just one set of actants imposing their will on others is required; it also requires that the others yield. This is exemplified by Jeff, as he seems to have reached an understanding at turn 22, though the learning activity goes on. He has not wholly yielded yet, it seems. Therefore, the students continue, making statements and conclusions together with the non-human actants, for example, when Jeff, the cursor, and the visualizations in turns 24 to 29 explore the relationships further. The actants seem to enrol with each other as the students and the visualization establish understanding (see turns 29 to 31). As the bubble shows "123" (in turn 29), this high number verifies Jeff's hypothesis articulated in line 26 . The actors have translated the relationships between the bubbles, the semiotic indication of countries, the meaning of place in the diagram, the amount or quantity of the concept, and the value of infant mortality into an understanding. The actors leave the problem space as the students and material actors have mobilized together. Again, the GVA seems to help the students complete their assignment by providing various data types (bubbles, etc.). By means of the emerging interactions that create a network between the actors, the information provided is translated into an understanding of the focus area, in this case, information on infant mortality. This underlines the importance of interactions between all actants, i.e., the learning content, concepts, graphics, cursor, and talking, to understanding how things and actions correspond. As long as this understanding is not established among the actants in the network, a problem space can be seen as emerging in the learning activity. This kind of problem space is characterized by the focus area in relation to the data type that is interacting with the actants. These two aspects are therefore central to completing the translation in the learning activity.

\section{Performer Dependence Linked to Data Use}

Third, a problem space that also appears frequently in the network concerns performer dependence and data use. This refers to the students' ability to understand concepts: to understand the visualizations and to use the information gained, i.e., make it into a new product by formulating written text. This is exemplified in the excerpt below. The students are involved in a learning activity in which they are trying to make conclusions concerning the concept of "population growth" aided by the visualization. They suppose that they should write down their assumptions.

Excerpt - network 3: This is what I say!

$\begin{array}{lll}\text { Turn Actant } & \text { Action } \\ 1 & \text { Moa: } & \begin{array}{l}\text { Aah, eh, mm, that is less. [She } \\ \text { points at the screen.] }\end{array} \\ 2 & \text { Screen: } \begin{array}{l}\text { Articulates infant mortality on the } \\ \text { x-axis and population growth on the } \\ \\ y \text {-axis and highlights Saudi Arabia }\end{array}\end{array}$
3 Moa:
So, if there is a country that has a lot of intercourse, or as they say sometimes "samslag," while at the same time people are dying, then they do not increase very much. It is as if one is born and one dies, then it must be like this: that you live a long time.
$/ \ldots / \ldots$
4 Moa Maybe we are supposed to write it as: there are a lot who are born and who get old. Do you get what I said?
5 Jeff: Yeah, I get it! [He shifts his gaze from the screen to his copybook and takes his pen in his hand to start writing.]
6 Moa: It means the same, if people die and babies are born.
7 Jeff: A lot of children are born and old people die. [He answers immediately and seems eager to write something down in his copybook immediately by putting the pencil on top of the paper.]
8 Moa: Nohoo! Hee, hee, the opposite.
9 Jeff: What! Ha, ha, you can't give birth to oldies.
10 Moa: Ha ha, I didn't say that either... Nooo, but if old people die at the same time as they are born, then it doesn't grow. [She says this with intensity.]
11 Jeff: If they are dead they can't be born. [Jeff's eyes glitter with mischief.]
12 Moa: But listen then! This is what I say. [She takes a pencil in her hand and starts to draw.]
13 Moa: Children are born and oldies die, then there is no growth.
14 Jeff: No [Jeff agrees], but they [he points at the computer] want to know why it is increasing!
Yes! And that is because you live long and that's the reason why so many are born. Because if the old ones should die...
16 Jeff:
Eeh, do you know what? Look! There are a lot of children born in poor countries ... [They start to write this down.]
17 Moa: $\quad$ But you don't live long then ... [They put their pencils down and the
15 Moa: interactions cease.]

Initially, the students seem to understand the concept that they are working on. Interessement occurs as Moa attempts to impose identities and roles on other actants on the screen. She enrols and aligns herself with what the screen articulates about population growth (see turns 1 and 2). She then mobilizes and explains this translation to Jeff in turn 3. In turn 4 she suggests what to write, and then asks Jeff if he understands what she means by the explanation. Jeff enrols by confirming in turn 5 that he understands the concept, but when he tries to mobilize using a larger network (with the pen and 
the pencil) and his eyes move away from the visualization and he looks down to start writing, he confuses "get old" with "old people die" (turn 7). This illustrates that it can be tricky to use the visualized data and transform it into text-based information. Moa, in turn 12, also tries to mobilize using her own drawing/image to explain her verbalization of the concept instead of writing down the conclusion by herself. This gives the impression that the students find it easier to enrol using a visualization to understand a concept. Again, in turn 14, Jeff enrols with Moa and agrees with her explanation, but he is also oriented towards the causes of population growth: for him it is not enough just to explain the concept. This shows how performer-dependent the use of data is. A small difference between the students in their interpretation of the concept, instruction, or visualization seems to affect the alignment and translations in the networks. The other thing that is obvious in the excerpt is the presence of the pencil (see turns $4,5,7,12$, and 17). It seems important to the students to enrol with the information and also to transform it using the pencil into a text-based answer on paper. The students try several times to do this, but when attempting to complete the act, they seem to lose their grip on the information and their understanding of it. This happens, for example, in turns 5 and 7, but also in turn 15 when Moa makes another effort to formulate an answer, which can be viewed as correct; however, Jeff seems to feel pressure to finally write an answer, and therefore tries to conclude in turn 16. The students end up in a problem space as soon as this happens and they try to write down the information (see turns 16 and 17). Moa immediately objects to the conclusion, probably due to meta-knowledge about life expectancy in less-developed countries, but the students are unable to resolve the issue without further problematization. This analysis illustrates the close relationship between the aspects performer dependence and data use when it is difficult to convert the visualized information into another modality, i.e., to formulate a written text from a visual analysis. Altogether, the analyses of the three excerpts in this section help us understand how various aspects distribute the problem spaces. The relationships giving rise to these problem spaces can be seen as aspects of: the task characteristics related to instructions/discretion; the data type related to the focus area; and performer dependence linked to data use.

\section{DISCUSSION}

The aim in this study is to determine the distribution of problem spaces in learning activities when GVA is employed in social science education. The analysis illustrates how the actants in various ways engage in the learning activities. The Vislets and instructions formulated by the teachers trigger actions in which the task, students, visualization, data types, etc., interact in such way that "proper" learning activities usually emerge within the network. The students are in this way provided with a consistent and measured view of the world with the help of sufficient tools, which is not always the case [13], [17]. Although the visual stories, the Vislets, constructed by the teachers may have differed in quality in terms of clarity, interactivity, etc., the students usually seem to succeed in their translations as long as they keep interacting with the Vislets. The analysis also illustrates though, how different aspects feature various problem spaces in the learning activities.

First, we can see how the instruction or level of discretion in relation to task characteristics is one of these aspects in the early phase of a problem space. Obviously, it is important for the students to thoroughly understand the task and its concepts, as in all other school assignments. However, it is clear that the students in these cases, in their efforts to understand the task characteristics, are supported by the GVA interactivity and visualizations. Together, the actants succeed in advancing within the problem space. This support differs from that offered by traditional school material that does not offer the same interactivity as these visualizations may afford.

Second, understanding the data type and its relationship to the focus area is another of these aspects. It is clear that the visualizations and students try to enrol with each other. To succeed, the interactivity gradually helps the students understand how the information is visualized. In this way, they are able to conclude and interpret something about the focus area. In relation to printed or more static school material, in which the students either have to understand the graphics from the start or probably have them explained by someone (i.e., the teacher), this is somewhat different. In this case, in which the technology is playing a part, a methodical investigation is possible, and an understanding of the focus area can be reached.

Third, it is illustrated how performer dependent the data use is, which also may feature various problem spaces. Even though the visualized data are interpreted correctly by the students, what they should do next with the insight from the data, this is dependent on the students' apprehension of what they usually do in such a situation in school. Traditionally, students' display their knowledge by writing down their understandings. This established notion of the students, seems to disrupt the translation [3]. It turns out to be difficult to transform the visualized information into another modality, to reformulate a visual analysis into written text.

In sum, this paper illustrates that even though problem spaces emerge, the interactions between the technology and the students facilitate the development of successful translations. This is held to be true as long as the visualization has a strong position within the network. It is when earlier established notions, for example, when conclusions reached on the basis of visualized data have to be presented in the form of handwritten text that the problem spaces seem to hinder translation. This is in line with earlier studies [12], [19] arguing that traditional writing pedagogy can disturb the development of insight from digital and multimodal texts. It seems as though the students' and teachers' notions of what is considered knowledge and of how knowledge can be visualized have to be modified. Together this confirms that a shift towards visual technology, such as Statistics eXplorer and other GVA is challenging schooling and traditional education [14]. It is recommended that the six aspects identified here be considered in order to avoid problem spaces in such learning activities. In particular the aspect of performer dependence and data use is central when considering how insights are to be documented. 


\section{CONCLUSIONS}

Geovisual analytics tools are found to support student learning, but they challenge the didactic design of the classroom. They can probably better facilitate knowledge building as students work with and analyze visualized data if pedagogy, teaching, and technology are better aligned and integrated. Important questions for further research concern how the didactic design can be improved in order to facilitate students' knowledge visualization.

\section{REFERENCES}

[1] R. Chakravarty, "Information literacy in the knowledge society: Empowering learners for a better tomorrow," p. 303.

[2] M. Hilbert and P. López, "The world's technological capacity to store, communicate, and compute information," Science, vol. 1 April, pp. 60-65, 2011.

[3] S. R. Ludvigsen, "What counts as knowledge: Learning to use categories in computer environments," Learning, Media and Technology, vol. 37, pp. 40-52, 2012.

[4] G. Andrienko, N. Andrienko, P. Jankowski, D. Keim, M. J. Kraak, A MacEachren et al., "Geovisual analytics for spatial decision support: Setting the research agenda," International Geographic Information Science, vol. 21, pp. 839-857, 2007.

[5] S. Ongstad, "Fag i endring. Om didaktisering av kunnskap," Fag og didaktikk i laererutdanning. Kunnskap i grenseland, 2006, pp. 19-57.

[6] T. J. Fenwick and R. Edwards, Actor-Network theory in Education, vol 1st ed. London; New York: Routledge, 2010.

[7] R. Halverson and R. B. Shapiro, "Technologies for education and technologies for learners: How information technologies are (and should be) changing schools," (WCER Working Paper No. 2012-6). Retrieved from University of Wisconsin-Madison, Wisconsin Center for Education Research website, 2012.

[8] A. Schleicher, "The case for 21st century learning," OECD Observer, pp. 42-43, 2011.

[9] H. Fleischer, "En elev - en dator: Kunskapsbildningens kvalitet och villkor i den datoriserade skolan," 2013.

[10] C. Lankshear and M. Knobel, "Introduction: Digital literacies-concepts, policies and practices," Digital Literacies: Concepts, Policies \& Practices, pp. 1-16, 2008.

[11] B. Latour, "On interobjectivity," Mind, Culture and Activity, vol. 3, pp. 228-255-246-269, 1996.

[12] A. Åkerfeldt, "Didaktisk design med digitala resurser: En studie av kunskapsrepresentationer i en digitaliserad skola," Stockholms Universitet, Samhällsvetenskapliga Fakulteten, Institutionen för Pedagogik Och Didaktik., 2014.

[13] R. Reynolds and M. Vinterek, "Globalization and classroom practice: Insights on learning about the world in Swedish and Australian schools," Nordidactica, pp. 104-130, 2013.

[14] A. Johansson Svensson, K. A. Rustand, S. Sofkova Hashemi, and T. Steffensen, "Students' use of semiotic structures in synchronous computer-mediated communication-an inter-scandinavian study," in Proc. ECTC-2013, The European Conference on Technology in the Classroom: "The Impact of Innovation: Technology and You", Brighton, UK, pp. 150-163.

[15] G. Andrienko, N. Andrienko, D. Keim, A. M. MacEachren, and S. Wrobel, "Challenging problems of geospatial visual analytics," Part Special Issue on Challenging Problems in Geovisual Analytics, vol. 22, pp. 251-256, 2011.

[16] L. Cherne, "Thoughts for the future," in Microcomputers and Children in the Primary School, R. Garland, Lewes: Falmer, 1982, p. 93.

[17] H. Rosling, A. R. Rönnlund, and O. Rosling, "New software brings statistics beyond the eye," OECD World Forum on Key Indicators, Teatro Massimo, Palermo, Italia, 2007.

[18] L. Stenliden and M. Jern, "Educating official statistics using geovisual analytics storytelling methods," in INTED2010 Proceedings, IATED.

[19] L. Stenliden, "Visual analytics in k 12 education - emerging dimensions of complexity," International Journal of Social, Behavioral, Educational, Economic, Business and Industrial Engineering, vol. 9, pp. 663-671, 2015.

[20] B. Latour, "Where are the missing masses? The sociology of a few mundane artefacts," in Shaping Technology/Building Society: Studies in Sociotechnical Change, W. Bijker and J. Law, Eds., ed Cambridge, Mass.: MIT Press, 1992, pp. 225-258.

[21] M. Callon, "Some elements of a sociology of translation: Domestication of the scallops and the fishermen of St Brieuc Bay," in Power, Action, and Belief : A New Sociology of Knowledge, J. Law, ed London: Routledge \& Kegan Paul, 1986, pp. 196-233.

[22] T. G. Gill and R. C. Hicks, "Task complexity and informing science: A synthesis," Informing Science Journal, vol. 9, 2006.

[23] C. Heath, J. Hindmarsh, and P. Luff, "Video in qualitative research: Analysing social interaction in everyday life," Los Angeles: SAGE, 2010.

[24] C. TechSmith, "Camtasia studio," vol. 7.1, Okemos, Michigan, 2010.

[25] B. Stafford and F. Terpak, "Revealing technologies/magical domains' in a box to images on a screen," Devices of Wonder: From the World in a Box to Images on a Screen, Los angeles: Getty Research Institute, 2001, pp. 1-109.

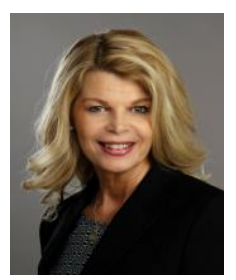

Linnéa Stenliden has a doctoral degree in educational sciences from the Department of Social and Welfare Studies, Linköping University, Sweden

Her research focuses on media technologies within teaching and learning processes in classroom studies She has also a longstanding interests in creative research methodologies, where she pays a special attention to posthuman research practices.

Dr. Stenliden is a member of EAPRIL - European Association for Practitioner Research on Improving Learning. She has been awarded with several research grants i.e.; the Swedish National Research Council, the Swedish government agency for innovation VINNOVA, Marcus and Amalia Wallenberg memorial fund. 